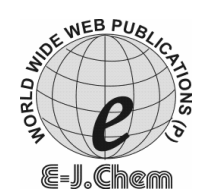

http://www.e-journals.net
ISSN: 0973-4945; CODEN ECJHAO

E-Journal of Chemistry 2008, 5(S1), 1048-1054

\title{
Synthesis and Characterization of Complex Compounds of Tetra-aza Macrocyclic Ligand
}

\author{
MAYURA A. PANCHBHAI ${ }^{\S} *$ L.J.PALIWAL and N.S. BHAVE \\ ${ }^{\S}$ Department of Chemistry, \\ Rashtrasant Tukdoji Maharaj Nagpur University, Nagpur - 440033, India. \\ Department of chemistry, Hislop College, Nagpur 440001, India. \\ mayyura22@yahoo.com
}

Received 19 April 2008: Accepted 10 June 2008

\begin{abstract}
This paper deals with the synthesis and characterization of a macrocyclic ligand (L) and its new-fangled complex compounds of the general formula $\left[\mathrm{M}-\mathrm{L} \mathrm{Cl}_{2}\right]$ for $\mathrm{M}=\mathrm{Ru}(\mathrm{III})$, and $[\mathrm{M}-\mathrm{L}]$ for $\mathrm{Pt}(\mathrm{II})$ and $\mathrm{Pd}(\mathrm{II})$ where $\mathrm{L}$ is a macrocyclic ligand resulted from the condensation reaction of ethylene diamine and ethyl acetoacetate. The ligand and its coordination compounds are formulated according to the chemical analysis, electronic, infrared, ${ }^{1} \mathrm{HNMR}$ and mass spectra, as well as magnetic susceptibility values.
\end{abstract}

Keywords: Azamacrocyclic ligand, Transition metal complexes, Platinum metals, Spectroscopy.

\section{Introduction}

The coordination chemistry of macrocyclic ligands is a fascinating area of research. The synthetic, kinetic and structural aspects ${ }^{1-2}$ of poly-aza macrocyclic complexes have received considerable attention and a variety of such systems have been synthesized ${ }^{3-9}$. The poly-aza macrocyclic complexes, particularly those of tetra-aza macrocycle along with the penta-aza and higher poly-aza macrocycles, have been widely studied in view of their potential for binding more than one metal ion ${ }^{10-12}$. The relationship of electronic properties and reactivity of these synthetic macrocyclic complexes to those of naturally occurring macrocycles, such as porphyrins ${ }^{13}$ and corrins, continues to promote great interest in their design and preparation.

The aim of this work is the production of novel macrocyclic ligand and its ruthenium(III) platinum(II) and palladium(II) complexes by using simple condensation method (Scheme 1). Thus, macrocyclic ligand and its complexes are synthesized and characterized by using different techniques. 


\section{Experimental}

All chemicals and solvents were reagent grade and used as received. C, H, N and M analyses were determined at the analytical unit of RSIC Chandigarh University, Chandigarh. IR spectra (as $\mathrm{KBr}$ pellets) were recorded $\left(4600-400 \mathrm{~cm}^{-1}\right.$ ) on a Perkin-Elmer 681 spectrophotometer. Electronic spectra in the $200-900 \mathrm{~nm}$ regions were recorded on a PerkinElmer 550 spectrophotometer. Mass spectra were recorded on Jeol SX-102(FAB), ${ }^{1} \mathrm{H}-\mathrm{NMR}$ spectra were obtained with a Perkin-Elmer R32-90 MHz spectrophotometer using TMS as internal standard and DMSO- $\mathrm{d}_{6}$ as solvent from CDRI, Lucknow. Magnetic susceptibility values were measured at $25^{\circ} \mathrm{C}$ by the Gouy's method using mercury tetrathiocyanatocobaltate(II) as the magnetic standard.

Preparation of macrocyclic ligand 5, 12 - dioxa - 7, 14-dimethyl - 1, 4, 8, 11 tetra-aza cyclotetradeca-1,8-diene (L)

1,2-Diaminoethane $(0.01 \mathrm{~mol}, 1.0 \mathrm{~g})$ in ethanol $(25 \mathrm{~mL})$, and ethyl acetoacetate $(0.01 \mathrm{~mol}, 1.2 \mathrm{~mL})$ dissolved in ethanol $(25 \mathrm{~mL})$, mixture of both the reactants were refluxed for $6 \mathrm{~h}$. Then volume concentrated on the steam bath until white colored crystals began to form. The product was purified by crystallization from hot alcohol and $1 \mathrm{~g}$ of activated charcoal (to remove colored impurities). Thus, white crystalline pure macrocyclic ligand was collected. (Scheme 1) (Yield: $1.8 \mathrm{~g} ; 75 \%$ ). The purity of the crystalline ligand has been checked by TLC.

\section{Preparation of $\left\{M(I I)-(L)-C l_{2}\right\}$}

To the hot ethanolic solution of ligand (L) $(0.01 \mathrm{~m} . \mathrm{mol}, 0.2 \mathrm{~g})$, hot ethanolic solution of metal chlorides [M-Cl $\mathrm{Cl}_{2} \cdot \mathrm{xH}_{2} \mathrm{O} ; 0.5 \mathrm{~g}$, where, $\mathrm{M}=\mathrm{Ru}(\mathrm{III}), \mathrm{Pt}(\mathrm{II})$ and $\left.\mathrm{Pd}(\mathrm{II})\right]$ with few drops of hydrochloric acid was added. The solution mixture was then refluxed for $2 \mathrm{~h}$. On cooling, colored precipitates were then filtered and washed with cold water and dried in vacuum (Scheme 1). The analytical data are given in Table 1.

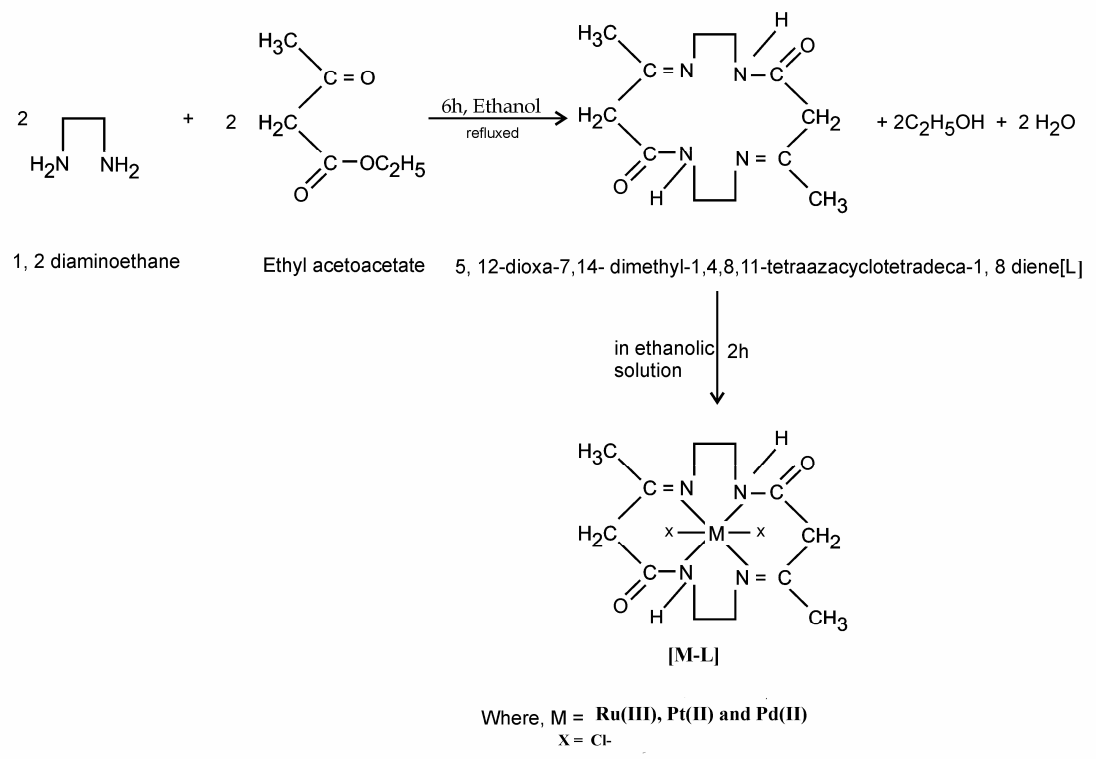

Scheme 1. 
Table 1. Analytical data of tetra-aza macrocyclic ligand (L) and its complexes.

\begin{tabular}{ccccccc}
\hline \multirow{2}{*}{ Compounds } & Colour & \multicolumn{3}{c}{ Elemental analysis, \% Calcd (found) } & \multirow{2}{*}{$\begin{array}{c}\text { Molecular } \\
\text { Weight }\end{array}$} \\
\cline { 3 - 6 } & & $\mathrm{M}$ & $\mathrm{C}$ & $\mathrm{H}$ & $\mathrm{N}$ & \\
\hline \multirow{2}{*}[\mathrm{L}]{} & White & - & 57.14 & 7.93 & 22.22 & \multirow{2}{*}{252} \\
& Dark & 23.82 & 33.96 & 4.71 & 13.20 & \multirow{2}{*}{424} \\
{$[\mathrm{Ru}-\mathrm{L}]$} & green & $(23.10)$ & $(32.99)$ & $(4.08)$ & $(14.46)$ & \\
& Pale & 43.62 & 32.21 & 4.47 & 12.52 & \multirow{2}{*}{448} \\
{$[\mathrm{Pt}-\mathrm{L}]$} & yellow & $(43.00)$ & $(32.09)$ & $(4.00)$ & $(12.99)$ & \\
& Brick & 29.6 & 40.22 & 5.58 & 15.64 & \multirow{2}{*}{358} \\
{$[\mathrm{Pd}-\mathrm{L}]$} & red & $(28.04)$ & $(40.09)$ & $(5.21)$ & $(15.99)$ & \\
& & & & & & \\
\hline
\end{tabular}

\section{Results and Discussion}

IR spectra

The preliminary identification of the macrocyclic ligand has been obtained from its IR spectrum, which shows the absence of uncondensed functional groups of ethylene diamine (i.e., stretching modes of starting materials) and suggests the formation of the proposed macrocycle. The appearance of strong absorption band in the region $1600-1650 \mathrm{~cm}^{-1}$ corresponds to $v>\mathrm{C}=\mathrm{N}$ stretching frequency (where, $\mathrm{v}=$ frequency). A single sharp band observed for the ligand at $3300 \mathrm{~cm}^{-1}$ corresponds to $\mathrm{vN}-\mathrm{H}$ of secondary $>\mathrm{CO}-\mathrm{NH}$ group. The absorption bands in the region 2900, $2950 \& 3000 \mathrm{~cm}^{-1}$ and $1380,1460 \& 1470 \mathrm{~cm}^{-1}$ in the ligand may reasonably, attributed to $\mathrm{vC}-\mathrm{H}$ stretching and $\mathrm{C}-\mathrm{H}$ bending vibration modes, respectively (Table 2).

The red shift of the complex compounds for $\mathrm{v}>\mathrm{C}=\mathrm{N}$ and $\mathrm{vN}-\mathrm{H}$ modes are found in the regions $1590-1600 \mathrm{~cm}^{-1}$ and $3250-3280 \mathrm{~cm}^{-1}$, respectively. However, the positions of these bands are consistent with those reported for the analogous complexes ${ }^{14}$. The negative shifts in $\mathrm{vN}-\mathrm{H}$ mode along with the appearance of new bands in the region $450-470 \mathrm{~cm}^{-1}$ assignable to $v \mathrm{M}-\mathrm{N}$ vibrations, suggest that the imide nitrogen is coordinating to the metal ions. The position of imide band, which does not undergo any change and the absence of a band attributable to vM-O $\left[500-550 \mathrm{~cm}^{-1}\right]$ vibrations indicate that the imide oxygen is noncoordinating. (Representative IR spectra of macrocyclic ligand and its representative coordination compound $\mathrm{Pd}(\mathrm{II})$ are given in the Figure 1).

Table 2. IR spectral data of given tetraaza macrocyclic ligand (L) and its complexes.

\begin{tabular}{|c|c|c|c|c|c|}
\hline \multirow{2}{*}{\multicolumn{2}{|c|}{ Groups }} & \multirow{2}{*}{$\begin{array}{l}\text { IR Frequencies }(v) \text { of the } \\
\text { macrocyclic ligand in } \\
\mathrm{cm}^{-1}\end{array}$} & \multicolumn{3}{|c|}{$\begin{array}{l}\text { IR Frequencies of the macrocyclic } \\
\text { complexes in } \mathrm{cm}^{-1}\end{array}$} \\
\hline & & & $\mathrm{Ru}$ & $\mathrm{Pt}$ & $\mathrm{Pd}$ \\
\hline & v N-H & $3300(\mathrm{~m})$ & $3250(\mathrm{~m})$ & $3265(\mathrm{~m})$ & $3280(\mathrm{~m})$ \\
\hline & $v>C=\mathrm{N}$ & $1600-1650(\mathrm{~s})$ & $1600(\mathrm{~m})$ & $1550(\mathrm{~m})$ & $1590(\mathrm{~m})$ \\
\hline & $\begin{array}{c}\text { V C-H } \\
\text { (Stretching) }\end{array}$ & $2900,2930 \& 2950(v)$ & $2850(\mathrm{~m})$ & $2885(\mathrm{~s})$ & $2890(\mathrm{~m})$ \\
\hline & C-H (bending) & $1380,1460 \& 1470(\mathrm{v})$ & $1410(\mathrm{~m})$ & $1450(\mathrm{v})$ & $1480(s)$ \\
\hline & M-N & --------- & $445(\mathrm{~m})$ & $450(s)$ & $470(\mathrm{~m})$ \\
\hline
\end{tabular}

[ $m=$ medium, $v=$ very strong, $s=$ sharp] 


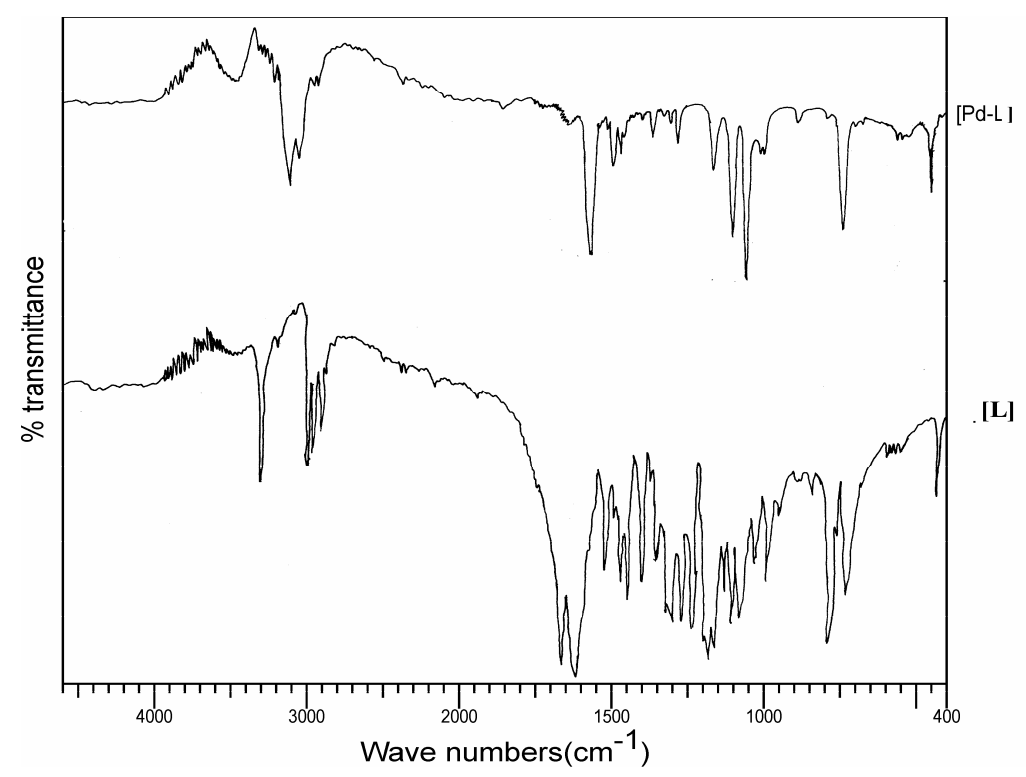

Figure 1. IR spectra of macrocyclic ligand and its complex [Pd-L]

\section{${ }^{l} H$ NMR spectra}

The ${ }^{1}$ HNMR spectrum of the macrocyclic ligand shows triplet in the region $\delta 1.10-\delta 1.15$ (where, $\delta=$ chemical shift) and singlet at $\delta 1.88$ corresponding to $\mathrm{CH}_{3}(6 \mathrm{H})$ protons and $\mathrm{CH}_{2}$ $(4 \mathrm{H})$ protons of acetoacetate moiety ${ }^{15}$, respectively. The ${ }^{1} \mathrm{HNMR}$ spectrum of $[\mathrm{L}]$ shows a broad signal observed at $\delta 8.53$ that may be attributed to imide protons ${ }^{16}(2 \mathrm{H})$. A quartet that observed in the region $\delta 3.91-\delta 3.98$ and singlet at $\delta 4.35$ possibly ascribed to methylene $\mathrm{CH}_{2}(8 \mathrm{H})$ protons ${ }^{17}$ of diaminoethane moiety.

The ${ }^{1} \mathrm{H}$ NMR spectra of the macrocyclic complexes show multiplets in the region $\delta 1.03$ -1.36 and $\delta 2.15-2.64$ attributed to $\mathrm{CH}_{3}(6 \mathrm{H})$ protons and the methylene protons $(4 \mathrm{H})$ of acetoacetate moiety, respectively. The transition metal complex shows broad singlet at 8.23 for Pt (II) macrocyclic complex whereas, small singlet is observed for Pd (II) $\delta 8.2$ which is attributable to imide protons $(2 \mathrm{H})$. Singlets and multiplets observed in the region $\delta 3.03-\delta$ 3.57 for macrocyclic complexes may possibly assigned to methylene protons $\left(>\mathrm{CH}_{2}\right)$ adjacent to nitrogen. The shift of the signals towards lower field is an identification of the coordination of macrocycle $\left({ }^{1} \mathrm{H}\right.$ NMR spectrum of the macrocylic ligand [L] is given in Figure 2 and representative ${ }^{1} \mathrm{HNMR}$ spectrum of $\mathrm{Pt}(\mathrm{II})$ macrocyclic complex is given in Figure 3).

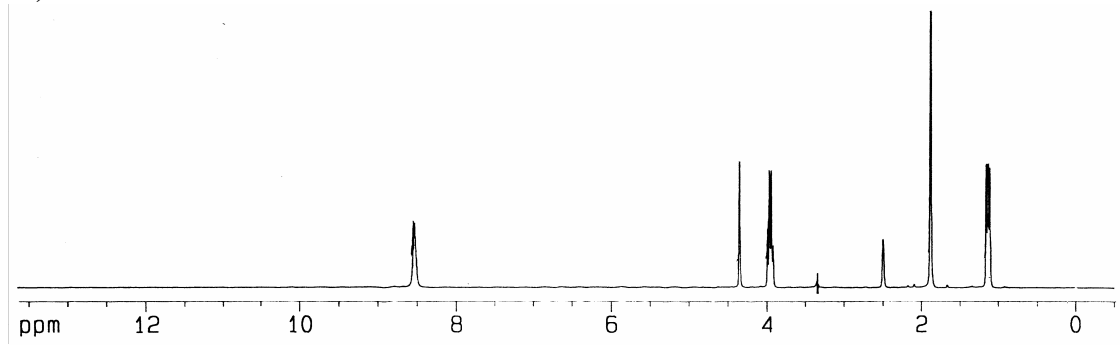

Figure 2. Proton NMR spectrum of macrocyclic ligand $[\mathrm{L}]$ 


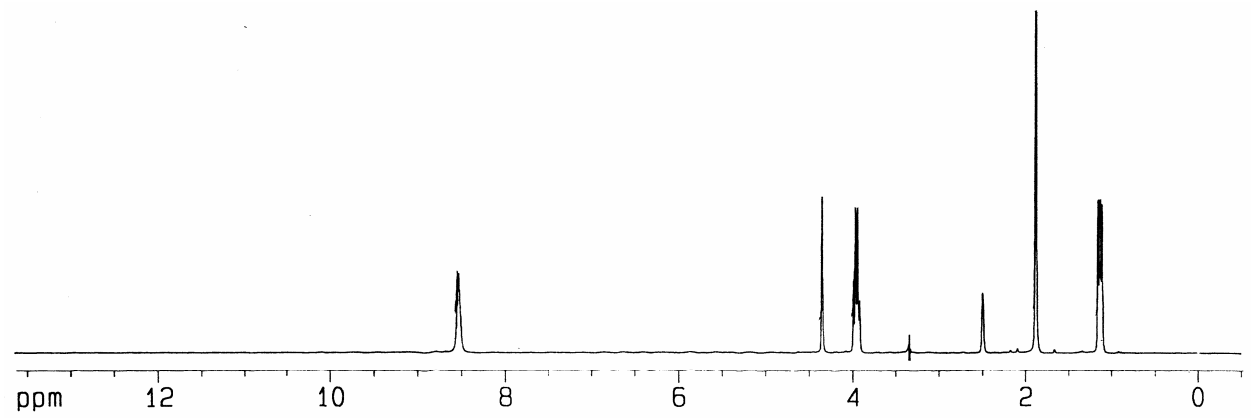

Figure 2. Proton NMR spectrum of macrocyclic ligand [L]

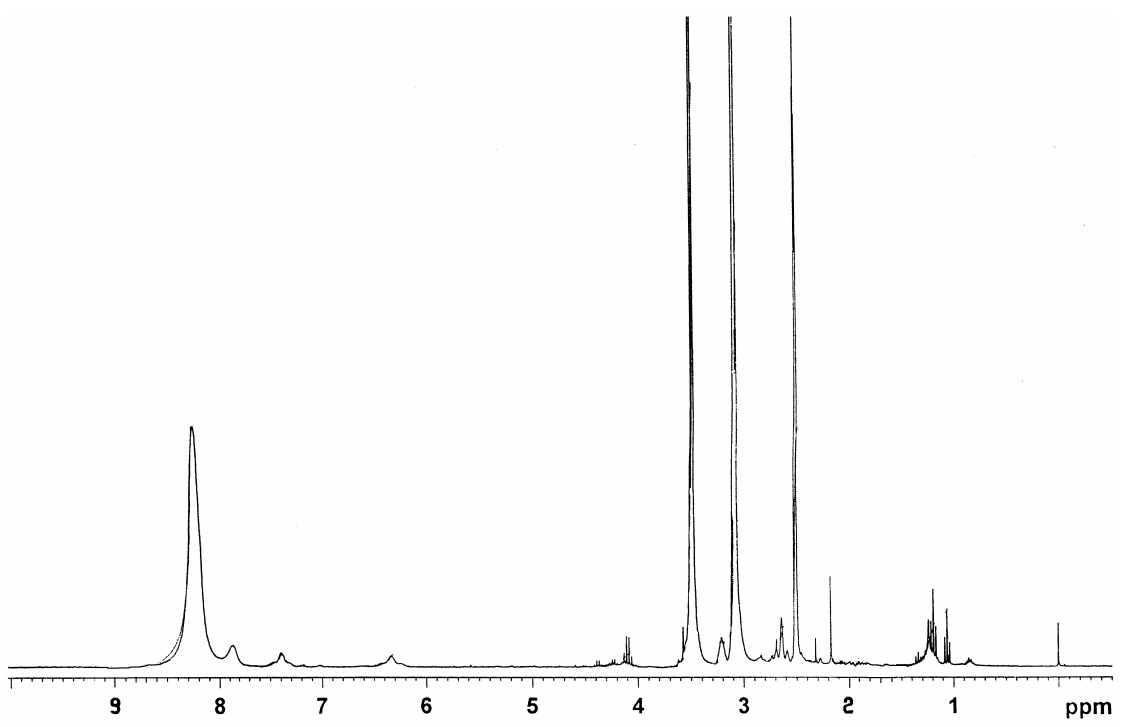

Figure 3. Proton NMR spectrum of macrocyclic complex[Pt-L]

\section{Mass spectra}

The determination of molecular weight of macrocyclic ligand (L) and its transition metal complexes by mass spectra has been very useful in completing their characterization. The fragmentation patterns of the ligand and its representative complex are given in the schemes 2 and 3 and shown in the Figures 4 and 5 respectively.

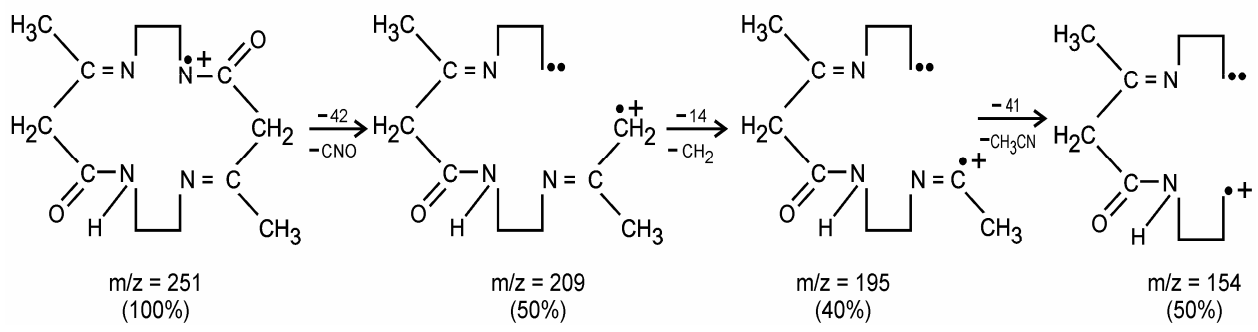

Scheme 2. Fragmentation pattern of macrocyclic ligand L 

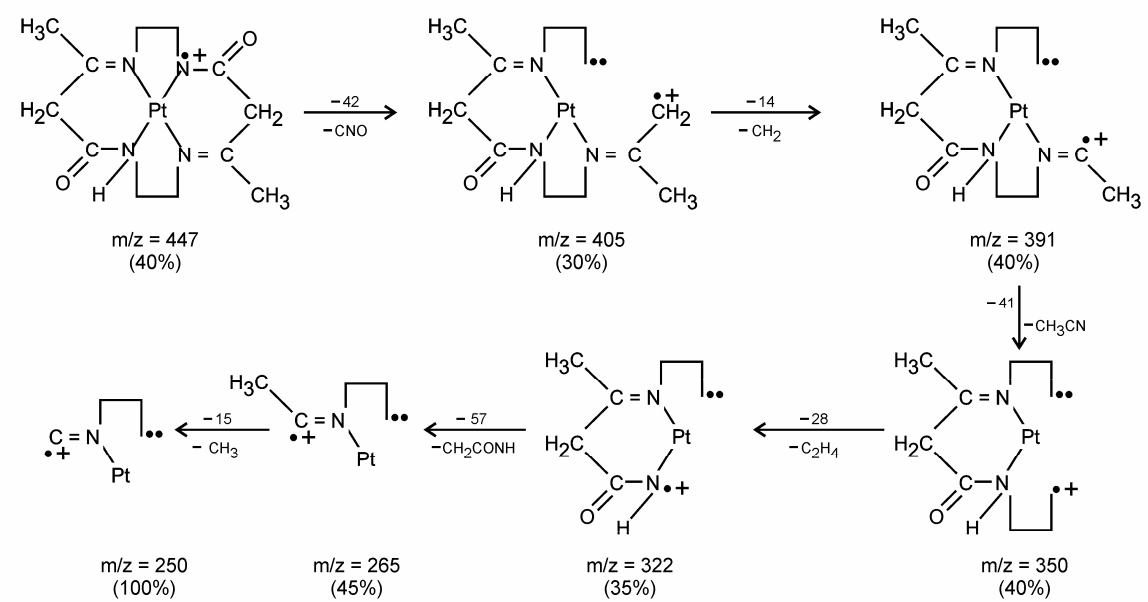

Scheme 3. Fragmentation pattern of macrocyclic complex pt-L
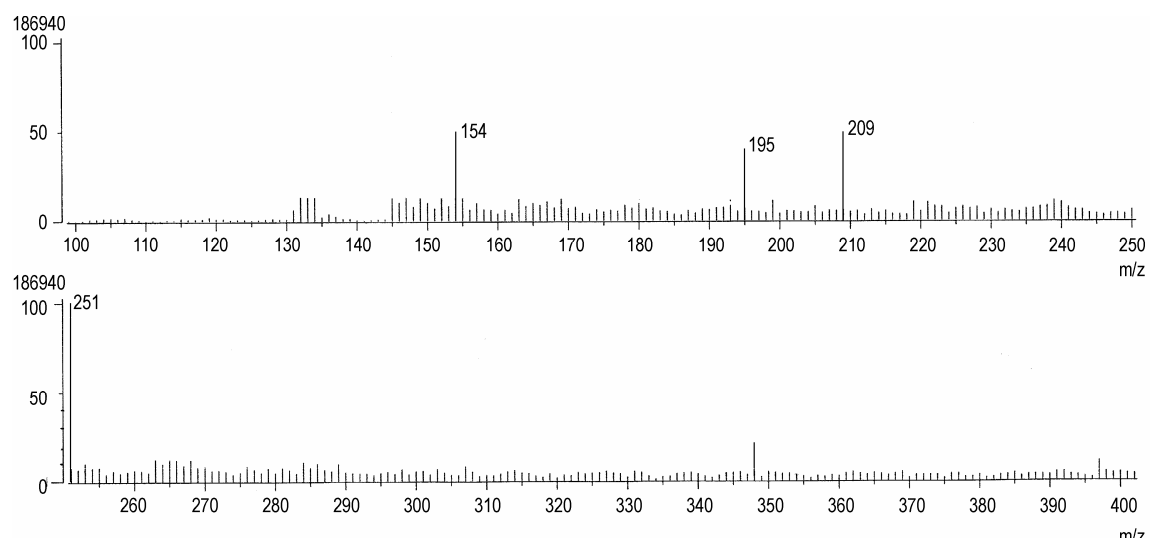

Figure 4. Mass spectrum of macrocyclic ligand [L]

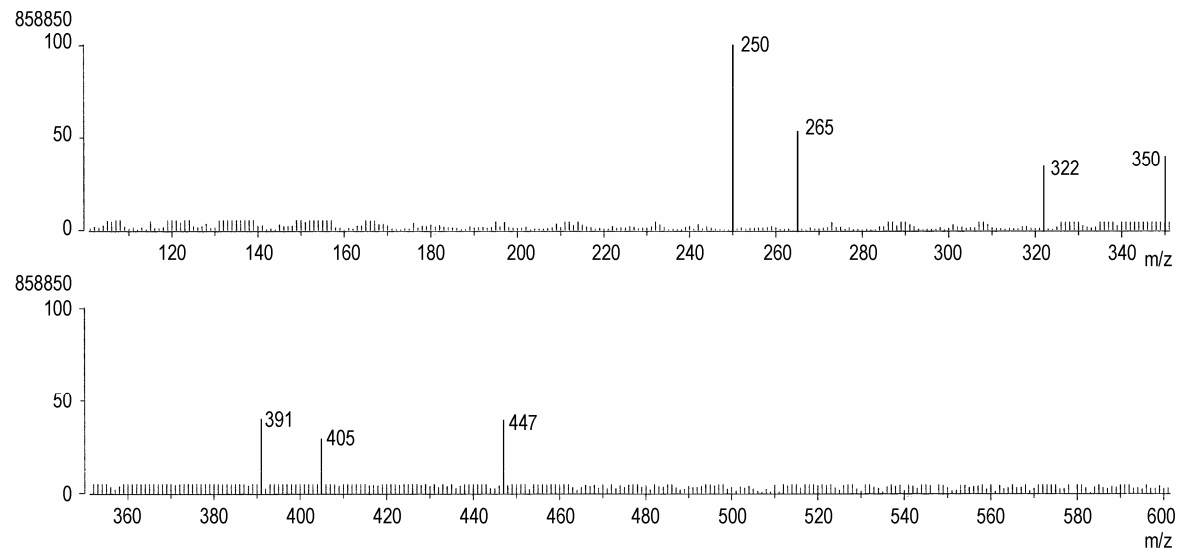

Figure 5. Mass spectrum of macrocyclic complex[Pt- L] 


\section{Electronic spectra}

The electronic spectral band in case of ruthenium complex is not observed due to charge transfer. The magnetic moment value of $\mathrm{Ru}(\mathrm{III})$ macrocyclic complex is found to be in the range of 1.7-1.85B.M.which is paramagnetic and lower than the spin only value (1.9 B.M.).

The $\mathrm{Pt}(\mathrm{II})$ macrocyclic complex is found to be diamagnetic and have $\mathrm{d}^{8}$ configuration implying a square planar geometry. $\mathrm{Pd}(\mathrm{II})$ macrocyclic complex ${ }^{18}$ is also found to be diamagnetic in nature.

\section{Conclusion}

The present investigation deals with the synthesis and characterization of tetraaza macrocyclic ligand and its transition metal complexes. On the basis of various physicochemical studies, the nature as well as to some extent, structure and stereochemistry of macrocyclic ligand and its complexes have been suggested.

\section{Acknowledgements}

Authors are thankful to the Head of the Chemistry Department RTMNU, RSIC Chandigarh and also CDRI, Lucknow for providing required facilities.

\section{References}

1 Izatt R M, Bradshaw J S, Nielsen S A, Lamb J D and Christensen J, J Chem Rev., $1985, \mathbf{8 5}, 271$.

2 Alexander V, Chem Rev., 1995, 95, 273.

3 Silversides Jon D, Allan Cheryll C and Archibald Stephen, J Dalton Trans., 2007,9, 971-978.

4 Inoue M B, Villegas C A, Asano K, Nakamura M, Inoue M and Fernando Q, Inorg Chem., 1992, 31, 2480.

5 Menon S C, Panda A, Singh H B and Butcher R J, Chem Commun., 2000,143.

6 Clifford T, Danby A M, Lightfoot P D, Richens T R and Hay W, J Chem Soc. Dalton Trans., 2001, 240.

7 Song B, Storr T, Liu S and Orvig C, J Inorg Chem., 2002, 685.

8 Mishra, A K and Chatal J F, New J Chem., 2001 ,25,336.

9 Tonei D M, Ware D C, Brothers P J, Plieger P G and Clark G R, Dalton Trans., 2006,152-158.

10 Suh M P and Kang S G, Inorg Chem., 1988, 27, 2544.

11 Suh M P, Shin W, Kim K and Kim J, Inorg Chem., 1984, 23, 618.

12 Silversides Jon D, Allan Cheryll C and Archibald Stephen J, Dalton Trans., 2007, 9, 971-978.

13 Chandra T, Kraft B J, Huffman J C and Zalesk J M, Inorg Chem., 2003, 42, 5158.

14 Nelson J, Murphy B P, Drew M G B, Yetes P C and Nelson S M, J Chem Soc. Dalton Trans., 1988,1001.

15 Shukla P R, Bhatt M and Sharma M C, J Indian Chem Soc., 1989, 66, 192.

16 Kumar D, Gupta P K and Syamal A, J Chem Sci., 2005, 117, 247-253.

17 Tabushi I, Okino H and Kuroda Y, Tetrahedron Lett., 1976, 48, 4339.

18 Lever A B P, Inorganic Electronic Spectroscopy; $2^{\text {nd }}$ Ed., Elsevier: Amsterdam, 1984. 


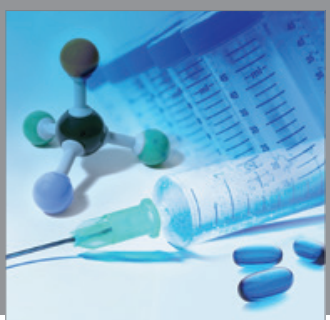

International Journal of

Medicinal Chemistry

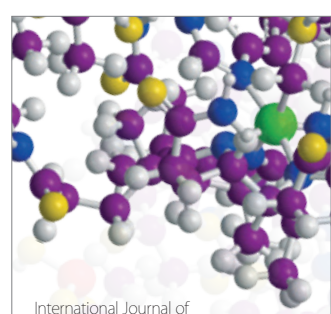

Carbohydrate Chemistry

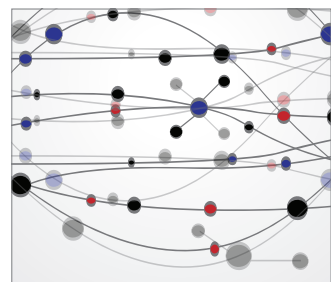

The Scientific World Journal
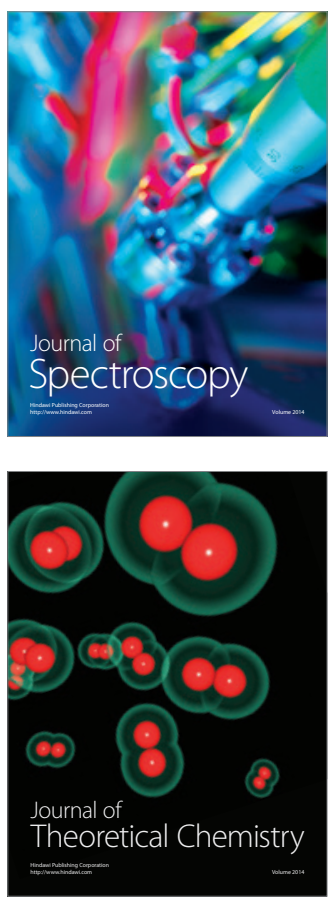
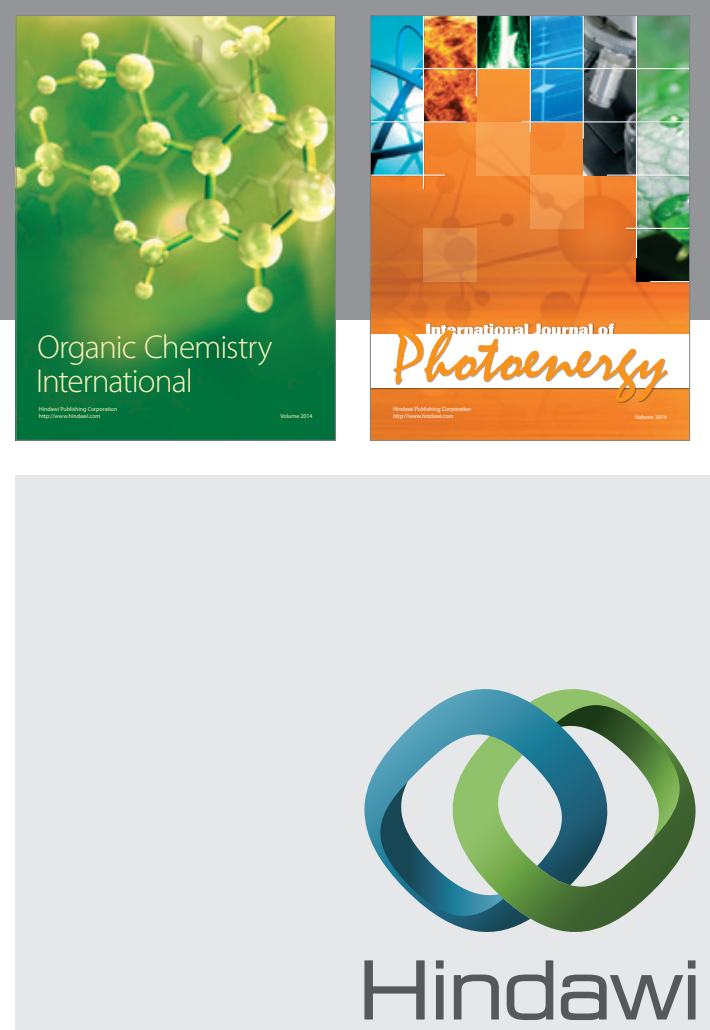

Submit your manuscripts at

http://www.hindawi.com
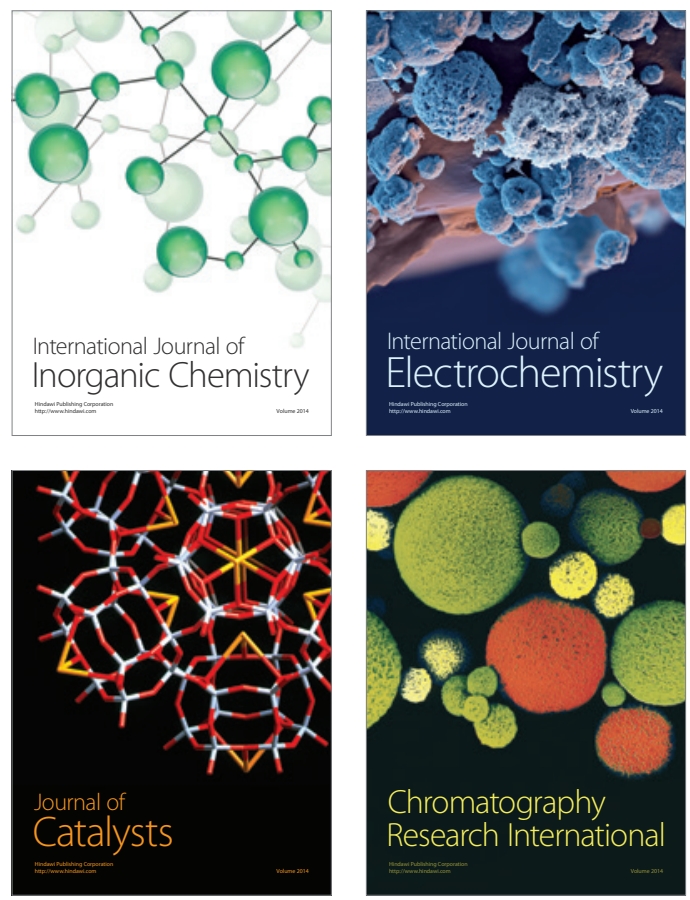
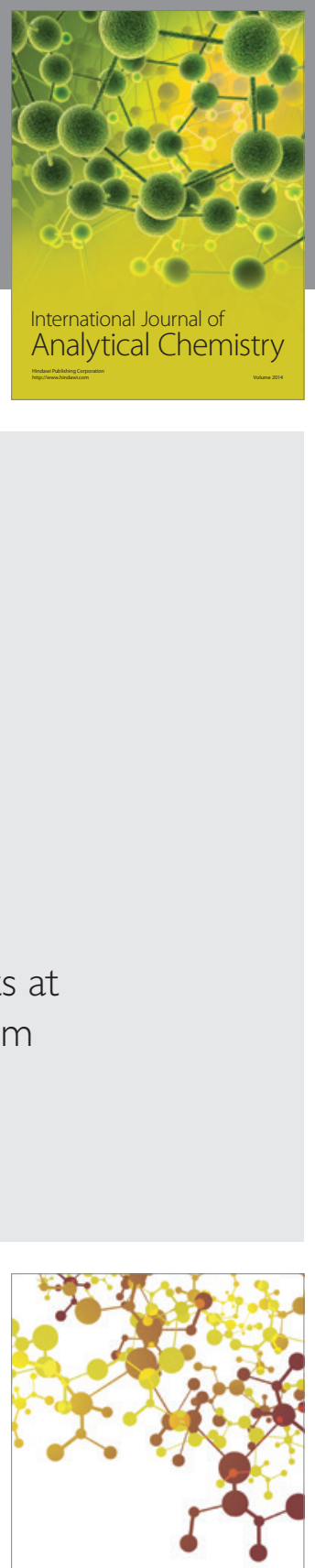

Journal of

Applied Chemistry
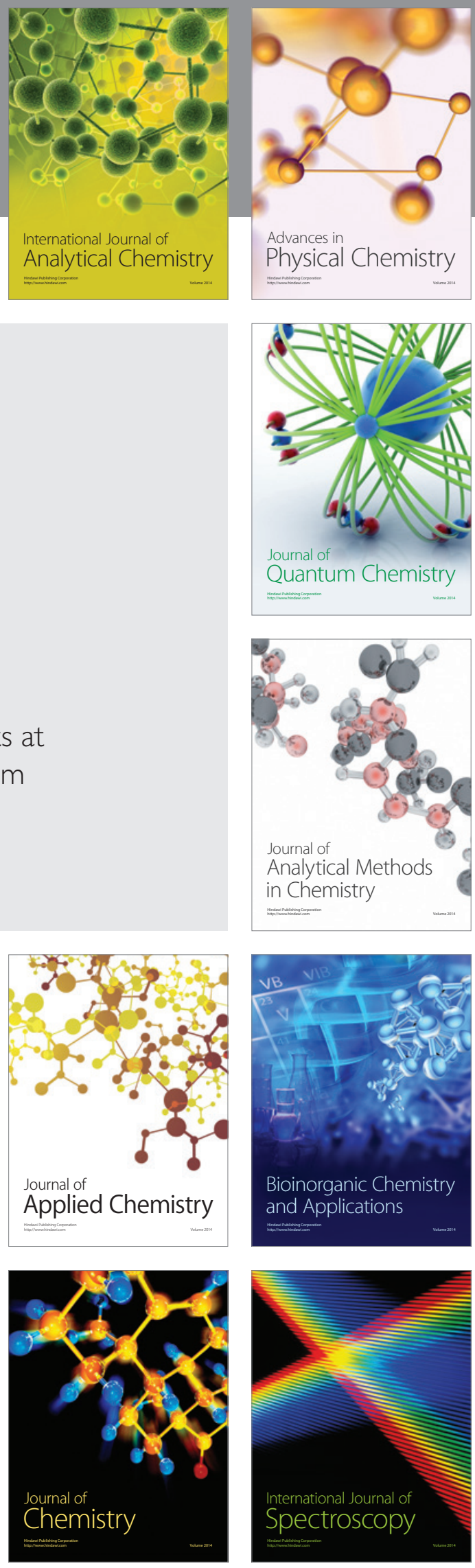